\title{
APOBEC3G/3A Expression in Human Immunodeficiency Virus Type 1-Infected Individuals Following Initiation of Antiretroviral Therapy Containing Cenicriviroc or Efavirenz
}

OPEN ACCESS

Edited by:

Guido Poli,

Università Vita-Salute

San Raffaele, Italy

Reviewed by:

Lucia Lopalco,

San Raffaele Hospital (IRCCS), Italy

Daria Trabattoni,

Università degli Studi

di Milano, Italy

*Correspondence:

Laura Fantuzzi

laura.fantuzzi@iss.it

tThese authors have contributed equally to this work.

Specialty section:

This article was submitted

to Viral Immunology,

a section of the journal

Frontiers in Immunology

Received: 11 April 2018

Accepted: 25 July 2018

Published: 08 August 2018

Citation:

Covino DA, Purificato C, Catapano L,

Galluzzo CM, Gauzzi MC, vella S,

Lefebvre E, Seyedkazemi S,

Andreotti $M$ and Fantuzzi L (2018)

APOBEC3G/3A Expression in Human

Immunodeficiency Virus Type

1-Infected Individuals Following

Initiation of Antiretroviral Therapy

Containing Cenicriviroc or Efavirenz.

Front. Immunol. 9:1839.

doi: 10.3389/fimmu.2018.01839

\author{
Daniela A. Covino', Cristina Purificato', Laura Catapano', Clementina M. Galluzzo', \\ Maria Cristina Gauzzi ${ }^{1}$, Stefano Vella ${ }^{1}$, Eric Lefebvre ${ }^{2}$, Star Seyedkazemi ${ }^{2}$, Mauro Andreotti ${ }^{1 \dagger}$ \\ and Laura Fantuzzi ${ }^{1 *+}$ \\ ${ }^{1}$ National Center for Global Health, Istituto Superiore di Sanità, Rome, Italy, ${ }^{2}$ Allergan plc, South San Francisco, CA, \\ United States
}

Apolipoprotein B mRNA editing enzyme catalytic polypeptide-like 3 (APOBEC3) family members are cytidine deaminases that play crucial roles in innate responses to retrovirus infection. The mechanisms by which some of these enzymes restrict human immunodeficiency virus type $1(\mathrm{HIV}-1)$ replication have been extensively investigated in vitro. However, little is known regarding how APOBEC3 proteins affect the pathogenesis of HIV-1 infection in vivo and how antiretroviral therapy influences their expression. In this work, a longitudinal analysis was performed to evaluate APOBEC3G/3A expression in peripheral blood mononuclear cells of antiretroviral-naive HIV-1-infected individuals treated with cenicriviroc (CVC) or efavirenz (EFV) at baseline and 4, 12, 24, and 48 weeks post-treatment follow-up. While APOBEC3G expression was unaffected by therapy, APOBEC3A levels increased in CVC but not EFV arm at week 48 of treatment. APOBEC3G expression correlated directly with CD4 ${ }^{+}$cell count and CD4 ${ }^{+} / \mathrm{CD} 8^{+}$cell ratio, whereas $A P O B E C 3 A$ levels inversely correlated with plasma soluble CD14. These findings suggest that higher APOBEC3G/3A levels may be associated with protective effects against HIV-1 disease progression and chronic inflammation and warrant further studies.

Keywords: АРОВЕСЗА, АРОВЕС3G, antiretroviral therapy, cenicriviroc, chronic inflammation, disease progression

\section{INTRODUCTION}

Highly active antiretroviral therapy dramatically reduced human immunodeficiency virus type 1 (HIV-1)-related morbidity and mortality and currently suppresses viral replication in the majority of compliant patients. Antiretroviral drug regimens usually containing three active drugs from two or more classes are recommended for virologic suppression (1). Initial drug combinations generally consist of two nucleoside reverse transcriptase inhibitors plus a third drug such as an integrase inhibitor, a non-nucleoside reverse transcriptase inhibitor, or a protease inhibitor. In case of virologic failure or multi-class resistance, drugs not generally recommended for initial therapy can be considered, such as CC chemokine receptor 5 (CCR5) antagonists. Despite viral suppression, signs of inflammation and immune activation persist in most patients (2-6). Cenicriviroc (CVC) is a smallmolecule CCR5 antagonist which has completed phase II of clinical development in HIV-1 infection 
$(7,8)$. It also inhibits CCR2, a receptor for CC chemokine ligand 2 (CCL2). The CCR2/CCL2 axis has been associated with various inflammatory diseases as well as with the high level of immune activation/inflammation and virus-associated disorders in HIV1-infected individuals (9-12).

The apolipoprotein B mRNA editing enzyme catalytic polypeptide-like 3 (APOBEC3; A3) proteins are cytidine deaminases playing a crucial role in antiviral innate immunity $(13,14)$. Among the seven human A3 enzymes (from A to H), A3G was identified as the cellular restriction factor responsible for inhibiting HIV-1 replication in the absence of the virally encoded protein virion infectivity factor (15). It is encapsidated into virions and blocks HIV-1 replication upon entry in newly infected cells mainly by causing C-to- $\mathrm{U}$ deamination on the single stranded viral DNA during reverse transcription, leading to either the hypermutation of the viral genome or the degradation of viral DNA by cellular repair mechanisms. Other family members, such as A3F and $\mathrm{A} 3 \mathrm{H}$, can be encapsidated into budding virions and exert their antiviral activity in newly infected cells. Conversely, A3A is the only A3 enzyme which can restrict infection directly in the target cells where it is endogenously expressed (16). The A3 proteins are expressed in a tissue- and cell type-specific manner (17-19). Peripheral blood leukocytes express transcripts for all the family members, with $\mathrm{A} 3 \mathrm{G}$ and $\mathrm{A} 3 \mathrm{~A}$ being the most highly represented (18). The former is greatly expressed in $\mathrm{CD} 4^{+} \mathrm{T}$ lymphocytes and myeloid cells (20), whereas expression of the latter is quite specific to myeloid lineage cells (21-24). While much has been learned about $\mathrm{A} 3$ proteins and their roles in $\mathrm{HIV}-1$ restriction in vitro, little is known about how they impact on the in vivo pathogenesis of HIV-1 in the host $(25,26)$. Although some studies investigated A3 expression (mainly A3G and A3F) and activity in $\mathrm{HIV}-1^{+}$ subjects and the correlations with clinical parameters of infection, scattered data are available on the impact of antiretroviral therapy. The aim of this study was to assess the expression of A3G and $\mathrm{A} 3 \mathrm{~A}$ in patients treated with $\mathrm{CVC}$ or conventional therapy and evaluate its association with virological, immunological, and inflammatory parameters.

\section{MATERIALS AND METHODS}

\section{Study Patients and Ethical Issues}

This study was exempt from ethics approval since it involved the secondary use of stored anonymized biological material from a subset of HIV- $1^{+}$patients enrolled in Study 202 (ClinicalTrials.gov NCT01338883), a multicenter 48-week phase $2 \mathrm{~b}$ trial comparing treatment with CVC at two different doses (100 and $200 \mathrm{mg}$ ) versus efavirenz (EFV) $600 \mathrm{mg}$, both in combination with emtricitabine/ tenofovir disoproxil fumarate, in antiretroviral treatment-naive, HIV-1-infected adults with CCR5-tropic virus (7). Study 202 was conducted in accordance with the Declaration of Helsinki, was approved by central or local institutional review boards or ethics committees at each study site, and a written informed consent was obtained from study participants. The trial included the measurement of biomarkers associated with inflammation and immune activation and sample storage for possible future studies. Available cryo-preserved peripheral blood mononuclear cell (PBMC) samples collected at baseline and after 4, 12, 24, and 48 weeks of treatment from participants who completed the follow-up period were used.

\section{Western Blot Analysis of A3 Proteins}

A3G and A3A expression was determined by western blot. Whole cell extracts were obtained by lysing PBMCs in RIPA buffer [150 mM NaCl, 50 mM Tris-Cl (pH 7.5), 1\% Nonidet P-40, 0.5\% sodium deoxycholate, and $0.1 \%$ sodium-dodecyl sulfate (SDS)] containing a cocktail of protease (Roche, Basel, Switzerland) and phosphatase inhibitors (Sigma-Aldrich, Milan, Italy) as previously described (21). Protein concentration was determined using the Bradford reagent (Bio-Rad, Milan, Italy) and a standard curve obtained with bovine serum albumin (Bio-Rad). Cell lysates (20 $\mu \mathrm{g}$ per lane) were fractionated on $10-12 \%$ SDS-PAGE and electroblotted to nitrocellulose filters (Protran BA 85, Schleicher \& Schuell, Keene, Netherlands). A reference curve with dose-scale concentration (20-10-5 $\mu \mathrm{g}$ ) of protein extracts derived from healthy donor PBMCs was used to assess the best primary and secondary antibody (Ab) dilutions and was included in each blot (data not shown). Membranes were incubated with 4-5\% fat-free milk dissolved in PBS-T (PBS $1 \times, 0.05 \%$ ) to block non-specific binding and then probed with the following Abs: anti-human A3A (rabbit polyclonal D23, Santa Cruz Biotechnology, Santa Cruz, CA, USA), anti-human A3G (rabbit polyclonal D9C6Z, Cell Signaling Technology, Beverly, MA, USA), and anti-actin (mouse monoclonal Abs-5, BD Biosciences, San Diego, CA, USA) as gel loading control. In some patients, A3G/A3A expression was confirmed by using a rabbit polyclonal anti-human A3G/A3A serum kindly provided by Dr. M. Malim (data not shown) (27). Blots were then incubated with appropriate secondary Abs conjugated with horseradish peroxidase (Santa Cruz Biotechnology) followed by Amersham ECL Western blot detection Reagent (GE Healthcare Life Sciences, Pittsburgh, PA, USA) or Pierce SuperSignal West Femto Substrate (Thermo Fisher Scientific, Waltham, MA, USA) according to the manufacturer's instructions. Levels of A3A, A3G, and actin proteins were detected and quantified by using Chemidoc XRS (Bio-Rad).

\section{Measurement of Virological, Immunological, and Inflammatory Parameters}

Human immunodeficiency virus type 1 RNA levels, blood $\mathrm{CD}^{+}$and $\mathrm{CD}^{+}$cell counts, immune activation (CD3/CD4/ $\mathrm{CD} 38$ and $\mathrm{CD} 3 / \mathrm{CD} 8 / \mathrm{CD} 38)$, and inflammatory [high sensitivity C-reactive protein (hs-CRP), D-dimer, fibrinogen, and soluble CD14 (sCD14)] biomarkers were assessed at baseline and after 4 (except for sCD14), 12, 24, and 48 weeks of treatment. Viral load was quantified by the TaqMan assay (Applied Biosciences, Life Technologies, Carlsbad, CA, USA). The immune activation marker CD38 was measured by flow cytometry using cryo-preserved PBMCs. D-dimer was quantified by immunoturbidimetric assay using a D-dimer assay (Liatest) kit (Diagnostica Stago, Asnieres, France), hs-CRP by immunochemiluminometric assay using a quantitative C-reactive protein kit (Roche Diagnostics), and fibrinogen by polymerization function by the Clauss method using the Stago Fibrinogen kit (Diagnostica Stago); these 
biomarkers were measured by LabCorp Clinical Trials (Cranford, NJ, USA). sCD14 was quantified by R\&D Systems using a solid phase sandwich ELISA with a human sCD14 Quantikine ELISA kit (R\&D Systems, Minneapolis, MN, USA). All the parameters used in the correlation analysis were previously reported (7).

\section{Statistical Analysis}

Intra-group variations between time points were assessed using Wilcoxon signed-rank tests, while the comparison between groups was done by the Mann-Whitney $U$ test. Non-parametric Spearman tests were used to determine correlation coefficients. Observations were considered statistically significant when $p<0.05$. SPSS version 24 (IBM Corp., Armonk, NY, USA) and GraphPad Prism version 7 (GraphPad Software, Inc., San Diego, CA, USA) were used for statistical analyses and graphs drawing.

\section{RESULTS}

We have performed a longitudinal analysis of $\mathrm{A} 3 \mathrm{G}$ and $\mathrm{A} 3 \mathrm{~A}$ expression in PBMCs from 41 Study 202 participants (26 from the CVC 200 arm and 15 from the EFV arm). Demographic and baseline clinical characteristics prior therapy initiation of the HIV-1-infected subjects analyzed are provided in Table 1. Total cell extracts were obtained from patient PBMCs collected before and 4, 12, 24, and 48 weeks after therapy initiation, and A3G and $\mathrm{A} 3 \mathrm{~A}$ protein levels were assessed by western blot and normalized to actin by densitometric analysis. A3G was detected in all the subjects analyzed, whereas $\mathrm{A} 3 \mathrm{~A}$ protein was under the detection limit of the assay in 5 out of 41 patients ( 2 and 3 in CVC and EFV arms, respectively). Expression of both $\mathrm{A} 3$ proteins at baseline did not significantly differ between the two arms (Table S1 in Supplementary Material). As shown in Figure 1A, expression of A3G was not altered over the 48 weeks in both treatment arms. Conversely, A3A levels were significantly increased at week 48 of treatment in the CVC arm $(p=0.001)$, whereas no significant differences were observed in the EFV arm (Figure 2A).

To ascertain whether the observed levels of A3G/A3A expression had any clinical significance, the subjects' viral loads, CD4 ${ }^{+}$ and $\mathrm{CD}^{+}$cell counts and $\mathrm{CD} 4^{+} / \mathrm{CD}^{+}$cell ratios, measured at baseline and at the end of the follow-up period (week 48), were examined as surrogate markers of disease progression. Table 2 summarizes these clinical parameters of study subjects during the treatment follow-up period. Spearman's correlation was used to estimate the association between these biomarkers and $A 3 \mathrm{G}$ or A3A protein levels. No correlation was found between A3G or A3A expression and viral load (data not shown). Baseline A3G levels correlated directly with baseline $\mathrm{CD} 4^{+}$cell counts (coefficient $=0.541 ; p=0.002)$ as well as $\mathrm{CD} 4^{+} / \mathrm{CD}^{+}$cell ratios at week 48 of treatment (coefficient $=0.451 ; p=0.01$ ) (Figures 1B,C). Conversely, no correlation was found between A3A expression and these parameters or monocyte counts (data not shown). Interestingly, baseline $\mathrm{A} 3 \mathrm{~A}$ levels inversely correlated with baseline sCD14 (coefficient $=-0.435 ; p=0.03$ ), and this effect was even stronger at week 48 of treatment (coefficient $=-0.46$; $p=0.009$ ) (Figures 2B,C). As shown in Figure 3, levels of sCD14 were significantly higher in EFV-treated subjects compared to

TABLE 1 | Demographic and baseline clinical characteristics of study subjects.

\begin{tabular}{|c|c|c|c|c|}
\hline Variable & CVC $200 \mathrm{mg}(n=26)$ & EFV $600 \mathrm{mg}(n=15)$ & All $(n=41)$ & $p^{a}$ \\
\hline \multicolumn{5}{|l|}{ Male sex } \\
\hline Number (percentage) & $26(100)$ & $12(80)$ & $38(93)$ & 0.023 \\
\hline \multicolumn{5}{|l|}{ Age } \\
\hline Years, median (range) & $38(21-57)$ & $35(20-49)$ & $37(20-57)$ & 0.255 \\
\hline \multicolumn{5}{|l|}{ Race } \\
\hline \multicolumn{5}{|l|}{ Number (percentage) } \\
\hline Black/African-American & $2(8)$ & $4(27)$ & $6(15)$ & 0.414 \\
\hline White & $20(77)$ & $11(73)$ & $31(76)$ & 0.106 \\
\hline Other & $4(15)$ & $0(0)$ & $4(10)$ & n.a. \\
\hline \multicolumn{5}{|l|}{ Ethnicity } \\
\hline \multicolumn{5}{|l|}{ Number (percentage) } \\
\hline Hispanic & $12(46)$ & 5 (33) & $17(41)$ & 0.090 \\
\hline Not Hispanic & $14(54)$ & $10(67)$ & $24(56)$ & 0.414 \\
\hline \multicolumn{5}{|l|}{ Viral load } \\
\hline $\log _{10}$ RNA copies/mL Median (range) & $4.65(3.55-5.37)$ & 4.28 (3.35-5.49) & $4.55(3.35-5.49)$ & 0.357 \\
\hline \multicolumn{5}{|l|}{ CD4 ${ }^{+}$count } \\
\hline Cells/ $\mu \mathrm{L}$, median (range) & $385(77-1,090)$ & $313(191-641)$ & $364(77-1,090)$ & 0.570 \\
\hline \multicolumn{5}{|l|}{ CD8+ count } \\
\hline Cells/ $\mu \mathrm{L}$, median (range) & $970(407-2,915)$ & $843(394-1,734)$ & $912(394-2,915)$ & 0.343 \\
\hline \multicolumn{5}{|l|}{$\mathrm{CD4}^{+} / \mathrm{CD}^{+}{ }^{+}$ratio } \\
\hline Median (range) & $0.40(0.10-1.10)$ & $0.40(0.20-0.90)$ & $0.40(0.10-1.10)$ & 0.773 \\
\hline \multicolumn{5}{|l|}{ sCD14 } \\
\hline pg/mL, median (range) & $1.75^{\mathrm{b}}(1.21-2.79)$ & $2.03(1.21-2.61)$ & $1.93(1.21-2.79)$ & 0.062 \\
\hline
\end{tabular}

CVC, cenicriviroc; EFV, efavirenz; n.a., not applicable; sCD14, soluble CD14.

${ }^{a}$ Calculated by Mann-Whitney $U$ test (continuous variables) or exact Pearson $\chi^{2}$ test (categorical variables).

${ }^{b}$ Baseline SCD14 was available for 23 subjects in the CVC $200 \mathrm{mg}$ arm. 


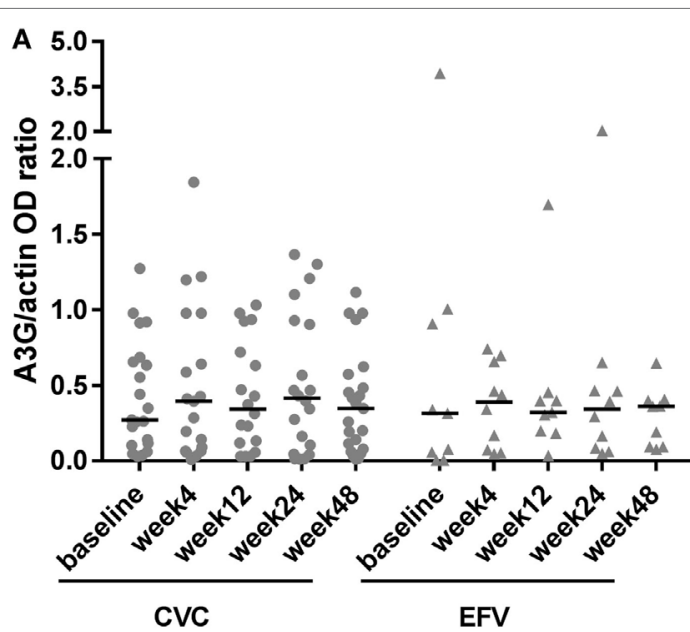

B

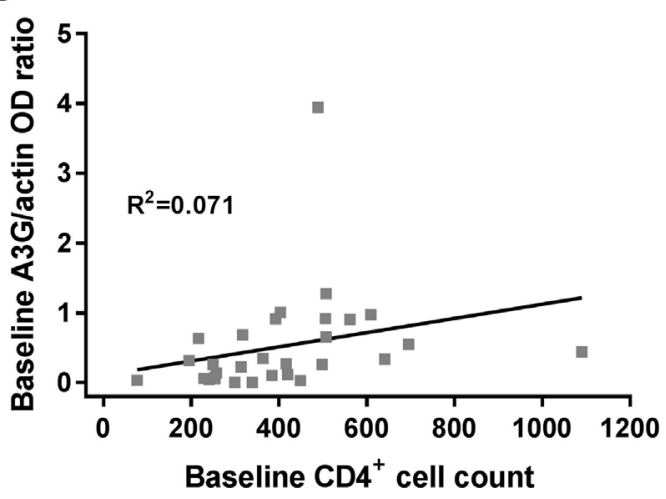

C

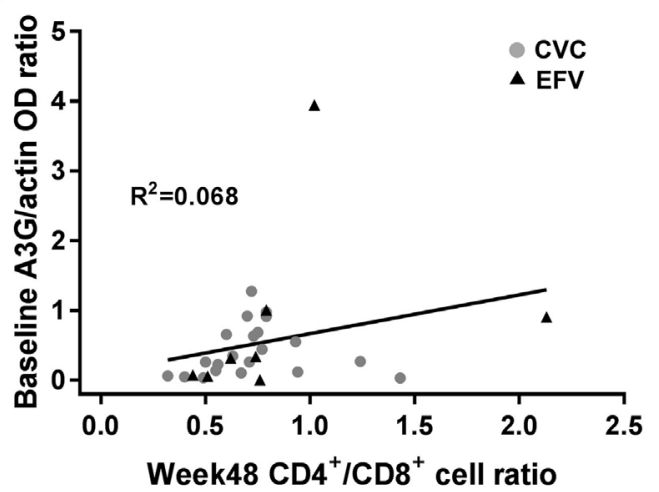

FIGURE 1 | A3G expression in cenicriviroc (CVC) and efavirenz (EFV) arms and correlation with surrogate markers of disease progression.

(A) Expression of A3G in peripheral blood mononuclear cells of subjects treated with CVC (circles) or EFV (triangles). The dot plots show the ratios of $\mathrm{A} 3 \mathrm{G}$ to actin $\mathrm{OD}$ determined by densitometry for each time point of the patients analyzed (CVC: $n=21$ baseline, $n=19$ week $4, n=18$ week 12 , $n=20$ week 24, $n=23$ week 48; EFV: $n=9$ baseline, $n=10$ week $4, n=9$ week 12, $n=10$ week 24, $n=9$ week 48). Median values (50th percentiles) are shown by the horizontal bars. (B) Correlation between baseline A3G levels and CD4+ cell counts $(n=30)$. (C) Correlation between baseline A3G levels and week $48 \mathrm{CD}^{+} / \mathrm{CD}^{+}$cell ratio $(n=29 ; \mathrm{CVC}: n=21$; EFV: $n=8)$. Gray circles and black triangles, CVC- and EFV-treated subjects, respectively. Statistical analysis was done using the Wilcoxon signed-rank test (A) and the non-parametric one-tailed Spearman's test to determine correlation coefficients (B,C).

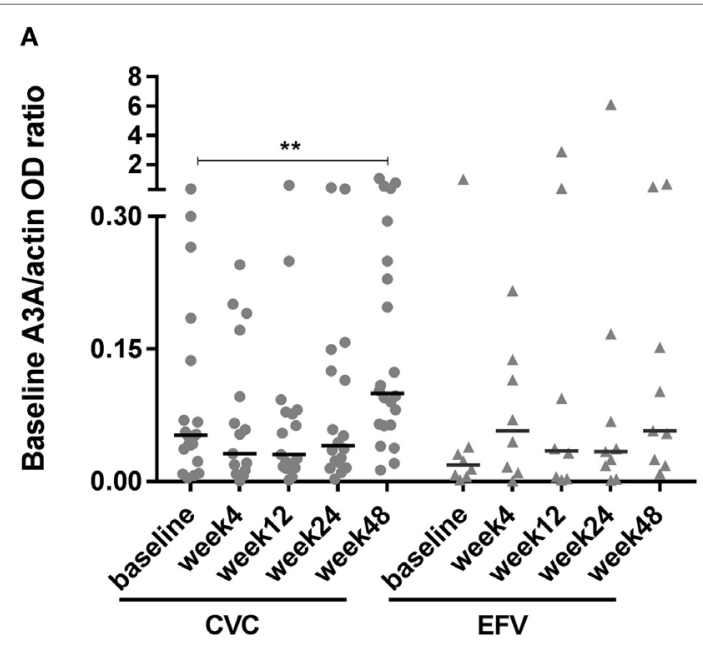

B

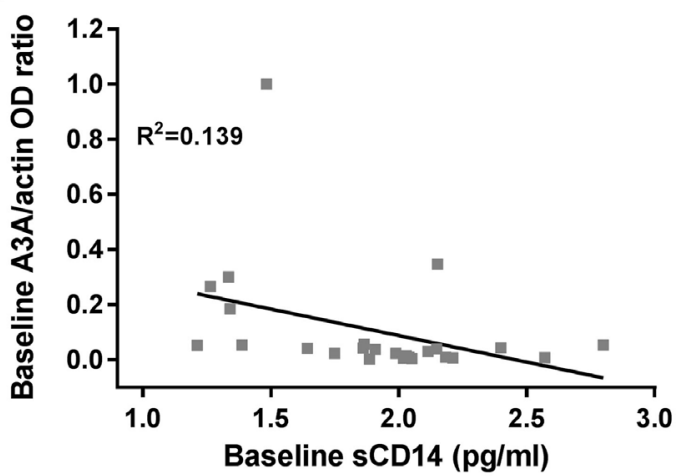

C

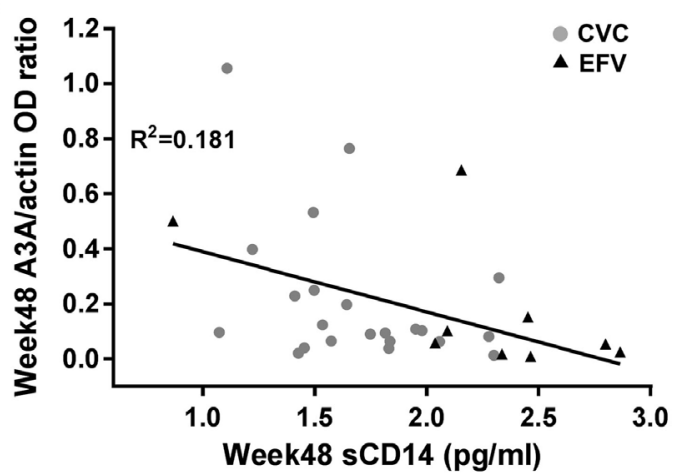

FIGURE 2 | A3A expression in cenicriviroc (CVC) and efavirenz (EFV) arms and correlation with the biomarker of inflammation soluble CD14 (sCD14). (A) Expression of $\mathrm{A} 3 \mathrm{~A}$ in peripheral blood mononuclear cells of subjects treated with CVC (circles) or EFV (triangles). The dot plots show the ratios of A3A to actin OD determined by densitometry for each time point of the patients analyzed (CVC: $n=20$ baseline, $n=17$ week $4, n=17$ week 12, $n=18$ week $24, n=22$ week 48; EFV: $n=8$ baseline, $n=8$ week $4, n=8$ week $12, n=9$ week 24, $n=9$ week 48). Median values (50th percentiles) are shown by the horizontal bars. ${ }^{\star \star} p=0.001$ (week 48 versus baseline). (B) Correlation between baseline A3A and sCD14 levels $(n=25)$. (C) Correlation between week 48 A3A and SCD14 levels ( $n=31$; CVC: $n=22$; EFV: $n=9$ ). Gray circles and black triangles, CVC- and EFV-treated subjects, respectively. Statistical analysis was done using the Wilcoxon signed-rank test (A) and the non-parametric one-tailed Spearman's test to determine correlation coefficients $(\mathbf{B}, \mathbf{C})$ 
TABLE 2 | Clinical parameters of study subjects during treatment follow-up.

\begin{tabular}{|c|c|c|c|c|c|}
\hline Variable & Time point of follow-up & CVC 200 mg $(n=26)$ & EFV $600 \mathrm{mg}(n=15)$ & All $(n=41)$ & $p^{a}$ \\
\hline Viral load & Week 4 & $2.51(1.28-2.97)$ & $2.03(1.28-3.27)$ & $2.30(1.28-3.27)$ & 0.066 \\
\hline $\log _{10}$ RNA copies/mL & Week 12 & $1.60(1.28-2.35)$ & $1.28^{b}(1.28-2.03)$ & 1.49 (1.28-2.35) & 0.040 \\
\hline \multirow[t]{2}{*}{ Median (range) } & Week 24 & $1.28(1.28-1.90)$ & $1.28(1.28-2.01)$ & $1.28(1.28-2.01)$ & 0.680 \\
\hline & Week 48 & $1.28(1.28-1.96)$ & $1.28(1.28-1.60)$ & $1.28(1.28-1.96)$ & 0.860 \\
\hline CD4 $^{+}$count & Week 4 & $439(174-1,045)$ & 441 (242-853) & $439(174-1,045)$ & 0.935 \\
\hline Cells $/ \mu \mathrm{L}$ & Week 12 & $526(213-1,339)$ & $501(180-641)$ & $506(180-1,339)$ & 0.159 \\
\hline \multirow[t]{2}{*}{ Median (range) } & Week 24 & $543(268-1,512)$ & 405 (222-697) & $481(222-1,512)$ & 0.261 \\
\hline & Week 48 & $573(316-1,205)$ & $501^{\circ}(332-907)$ & $548(316-1,205)$ & 0.183 \\
\hline CD8+ count & Week 4 & $1,005(430-2,196)$ & 737 (474-1,180) & $878(430-2,196)$ & 0.028 \\
\hline Cells $/ \mu \mathrm{L}$ & Week 12 & $934(431-1,611)$ & $814(308-1,067)$ & $823(308-1,611)$ & 0.042 \\
\hline \multirow[t]{2}{*}{ Median (range) } & Week 24 & $932(438-1,597)$ & $701(393-1,015)$ & $765(393-1,597)$ & 0.012 \\
\hline & Week 48 & $831(466-1,756)$ & $797^{\circ}(380-1,323)$ & $829(380-1,756)$ & 0.294 \\
\hline $\mathrm{CD4}^{+} / \mathrm{CD}^{+}{ }^{+}$ratio & Week 4 & $0.45(0.10-1.20)$ & $0.60(0.40-0.90)$ & $0.50(0.10-1.20)$ & 0.100 \\
\hline \multirow[t]{3}{*}{ Median (range) } & Week 12 & $0.60(0.20-1.40)$ & $0.60(0.40-1.60)$ & $0.60(0.20-1.60)$ & 0.493 \\
\hline & Week 24 & $0.60(0.20-1.40)$ & $0.60(0.50-1.70)$ & $0.60(0.20-1.70)$ & 0.574 \\
\hline & Week 48 & $0.70(0.30-1.40)$ & $0.60^{\circ}(0.40-2.10)$ & $0.70(0.30-2.10)$ & 0.616 \\
\hline
\end{tabular}

CVC, cenicriviroc; EFV, efavirenz.

${ }^{a}$ Calculated by Mann-Whitney $U$ test.

${ }^{b}$ Week 12 HIV-1 RNA was available for 14 subjects in the EFV $600 \mathrm{mg}$ arm.

'Week $48 \mathrm{CD}^{+}$and $C D 8^{+}$counts were available for 14 subjects in the EFV $600 \mathrm{mg}$ arm.

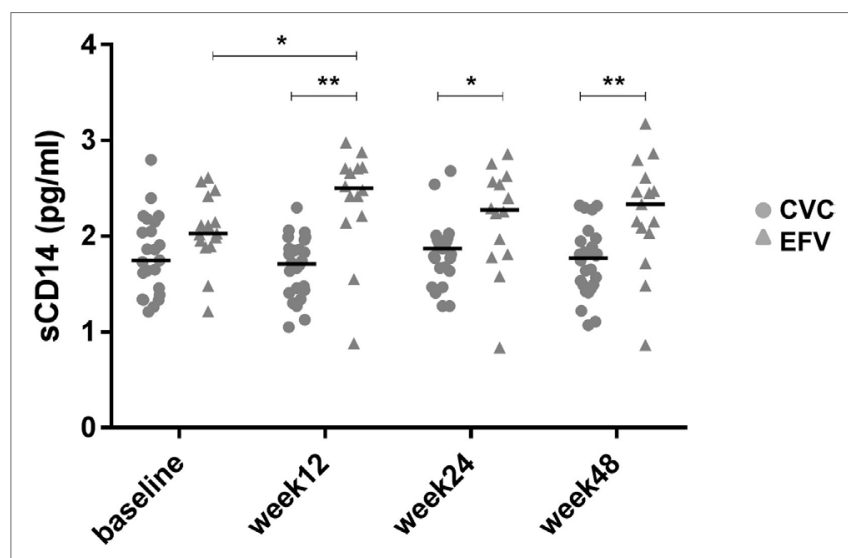

FIGURE 3 | Levels of soluble CD14 (sCD14) in cenicriviroc (CVC) and efavirenz (EFV) arms. The dot plots show plasma sCD14 levels measured by ELISA at each time point of the patients analyzed (CVC: $n=23$ baseline, $n=26$ week 12, $n=25$ week 24, $n=26$ week 48; EFV: $n=15$ baseline, $n=14$ week 12, $n=14$ week 24, $n=15$ week 48). Median values (50th percentiles) are shown by the horizontal bars. Statistical analysis was done using the Mann-Whitney $U$ or Wilcoxon signed-rank tests for unpaired or paired data. ${ }^{*} p<0.05 ;{ }^{* *} p<0.005$.

CVC arm at weeks 12, 24, and 48 of treatment but not at baseline (see Table 1). Moreover, sCD14 levels were significantly increased at week 12 of treatment in the EFV arm $(p=0.026)$, whereas no changes were observed during the follow-up period in the CVC arm. No correlation was observed between A3A expression and other non-specific markers of inflammation, namely hs-CRP, D-dimer, and fibrinogen, as well as the activation marker CD38 expressed on $\mathrm{CD}^{+}$and $\mathrm{CD}^{+}$lymphocytes (data not shown), which did not differ across the arms during follow-up (see Table S2 in Supplementary Material).

\section{DISCUSSION}

The role of A3s in regulating HIV-1 replication in vivo is unclear. Previous studies have addressed A3G (and A3F) expression and function in PBMCs of $\mathrm{HIV}-1^{+}$subjects by quantifying A3 transcripts or editing in HIV-1 DNA. A positive correlation of A3G mRNA levels and/or viral DNA hypermutation with $\mathrm{CD} 4^{+}$ cell count of $\mathrm{HIV}-1^{+}$subjects and a negative correlation with viral load were identified in some studies (28-32) but not in others $(33,34)$. Higher levels of A3G were also observed in HIV-1exposed uninfected individuals compared to healthy control or infected subjects $(28,35)$ and in long-term non-progressors compared to HIV-1-uninfected individuals and normal progressors (30). However, not all the studies were concordant with these associations (36), and higher A3G levels were found in HIV-1compared to $\mathrm{HIV}-1^{+}$individuals, including matched pre- and post-infection samples from the same subjects, suggesting that A3G transcription may be downregulated upon infection (33). These contrasting results might be due to either technical issues or the size/characteristics of the cohorts studied. In this study, we conducted a longitudinal ex vivo analysis of A3G and A3A protein expression in PBMCs of HIV-1-infected individuals at baseline and at various times of antiretroviral therapy with CVC or EFV. Our results highlight a direct correlation between baseline $\mathrm{A} 3 \mathrm{G}$ levels and either baseline $\mathrm{CD} 4^{+}$cell counts, as previously reported by others $(28,29,37)$, or $\mathrm{CD}^{+} / \mathrm{CD} 8^{+}$cell ratios at week 48 of treatment. The former is a well-known predictor of disease progression, and even the latter has been proposed in recent years as a marker of immune dysfunction, viral reservoir size, and a prognostic indicator for non-AIDS mortality (38). Although correlation does not necessarily indicate causation, these results support the hypothesis that enhanced A3G expression, even if not correlating with viral load, may provide protective effects against disease progression through the association with either increased 
$\mathrm{CD} 4^{+}$cell count in therapy naive patients or $\mathrm{CD} 4^{+} / \mathrm{CD} 8^{+}$cell ratio during antiretroviral treatment.

To our knowledge, this study is the first to show that therapy initiation with diverse antiretroviral regimens can differently affect the expression of A3 proteins. Indeed, treatment with CVC, but not with EFV, determined an increase of A3A, but not A3G, expression. Although type I IFNs are the best characterized inducers of $\mathrm{A} 3 \mathrm{~A}$ expression, its role in the modulation of A3A levels in CVC-treated subjects was not investigated in this study. However, other stimuli have been shown to modulate the expression of this protein in an IFN-independent manner (19). In particular, our group demonstrated that endogenous CCL2 represents an autocrine factor acting as a negative regulator of $\mathrm{A} 3 \mathrm{~A}$ expression in macrophages. Indeed, the neutralization of this chemokine determined a specific increase in $\mathrm{A} 3 \mathrm{~A}$, but not $\mathrm{A} 3 \mathrm{G}$, expression in either uninfected or HIV-1-infected monocyte-derived macrophages, and this effect was associated with a decrease of viral replication. Treatment with anti-IFN- $\alpha / \beta$ serum demonstrated that CCL2 blocking-mediated A3A induction was type I IFN independent $(21,39)$. Thus, the increase of $\mathrm{A} 3 \mathrm{~A}$ levels induced by CVC treatment may be a consequence of the CCR2 antagonistic activity of the drug. This is further supported by the lack of induction of A3G expression following CVC treatment. These results add new insights into the notion that blocking the CCR2/CCL2 axis may regulate the expression of this innate intracellular viral antagonist. Unlike $\mathrm{A} 3 \mathrm{G}$, in vivo $\mathrm{A} 3 \mathrm{~A}$ expression in $\mathrm{HIV}-1^{+}$subjects has been poorly investigated. A3A transcripts were shown to be downregulated after initiation of antiretroviral therapy in whole blood samples from 10 Ugandans with AIDS (40). In addition, A3A baseline expression in PBMCs from $\mathrm{HIV}$-1-infected patients was found to significantly correlate with viral load decline observed following 3 weeks of treatment with pegylated IFN- $\alpha-2 \mathrm{a}$ (41). Although in the patients' cohort analyzed in this study A3A levels do not correlate with either viral load or $\mathrm{CD}^{+} / \mathrm{CD}^{+}$cell counts and ratios, an inverse correlation was found between A3A expression and sCD14 levels. CD14 is a coreceptor for LPS and its soluble form is a marker of monocyte activation, and represents an independent predictor of morbidity and mortality in people with HIV-1 infection (2). When considering the association between $\mathrm{A} 3 \mathrm{~A}$ and $\mathrm{SCD} 14$ within the two arms, we did not detect a significant correlation (data not shown), likely due to the limited number of subjects in each arm.

Chronic inflammation is considered nowadays a driving force of immune dysfunction and AIDS progression. A residual chronic immune activation persists even in HIV-1-infected patients in which viral replication is inhibited by antiretroviral therapy. In fact, persistent latently infected cells contribute to the continuous activation of immune cells, establishing a dangerous vicious cycle between viral persistence and immune activation which contributes to the development of pathological conditions and hinders a complete remission (2). Although virologic success and $\mathrm{CD} 4^{+}$cell count increase were similar across CVC and EFV arms (7), lower levels of sCD14 were present in the CVC-treated group, suggesting the potential anti-inflammatory effects of this drug. This was confirmed in a very recent study in which virally suppressed chronic HIV-1-infected individuals were treated with CVC for 24 weeks (42). Despite the power of our study was limited by the small number of subjects analyzed, the increased expression of $\mathrm{A} 3 \mathrm{~A}$ in the CVC-treated group suggests an unprecedented link between decreased inflammation and innate antiviral responses. $\mathrm{A} 3 \mathrm{~A}$ is mainly expressed by monocytes, but the low amount of patient's cells available imposed to perform the analysis of $\mathrm{A} 3 \mathrm{~A}$ levels on whole PBMCs. Additional work with larger cohorts and purified leukocyte populations is needed to robustly define the association between $\mathrm{A} 3 \mathrm{~A}$ expression and inflammation.

\section{ETHICS STATEMENT}

This study was exempt from ethics approval since it involved the secondary use of stored anonymized biological material from a subset of $\mathrm{HIV}-1^{+}$patients enrolled in Study 202 (ClinicalTrials.gov NCT01338883), a multicenter 48 -week phase $2 \mathrm{~b}$ trial comparing treatment with CVC at two different doses (100 and $200 \mathrm{mg}$ ) versus efavirenz (EFV) $600 \mathrm{mg}$, both in combination with emtricitabine/ tenofovir disoproxil fumarate, in antiretroviral treatment-naive, HIV-1-infected adults with CCR5-tropic virus (7). Study 202 was conducted in accordance with the Declaration of Helsinki, was approved by central or local institutional review boards or ethics committees at each study site, and a written informed consent was obtained from study participants. The trial included the measurement of biomarkers associated with inflammation and immune activation and sample storage for possible future studies. Available cryo-preserved peripheral blood mononuclear cell (PBMC) samples collected at baseline and after $4,12,24$, and 48 weeks of treatment from participants who completed the follow-up period were used.

\section{AUTHOR CONTRIBUTIONS}

DC designed and performed experiments, analyzed and interpreted the data, designed the figures, and contributed to write the manuscript. CP, LC, and CG performed experiments. MG contributed to data interpretation and manuscript writing. SV provided scientific advice and edited the manuscript. EL and SS contributed patients samples and clinical data. MA and LF conceived and designed the study, analyzed and interpreted the data, and wrote the manuscript. All the authors reviewed and approved the final manuscript.

\section{ACKNOWLEDGMENTS}

We thank Michael H. Malim for providing the anti-A3G/A3A serum, Bill Tan for assistance with patients data, and Daniela Diamanti and Fabiola Diamanti for excellent technical support.

\section{FUNDING}

This work was supported by a grant from the Italian Ministry of Health, Ricerca Finalizzata RF-2011-02347224 to LF.

\section{SUPPLEMENTARY MATERIAL}

The Supplementary Material for this article can be found online at https:/www.frontiersin.org/articles/10.3389/fimmu.2018.01839/ full\#supplementary-material. 


\section{REFERENCES}

1. Cihlar T, Fordyce M. Current status and prospects of HIV treatment. Curr Opin Virol (2016) 18:50-6. doi:10.1016/j.coviro.2016.03.004

2. Klatt NR, Chomont N, Douek DC, Deeks SG. Immune activation and HIV persistence: implications for curative approaches to HIV infection. Immunol Rev (2013) 254:326-42. doi:10.1111/imr.12065

3. Hileman CO, Funderburg NT. Inflammation, immune activation, and antiretroviral therapy in HIV. Curr HIV/AIDS Rep (2017) 14:93-100. doi:10.1007/ s11904-017-0356-x

4. Hunt PW, Lee SA, Siedner MJ. Immunologic biomarkers, morbidity, and mortality in treated HIV infection. J Infect Dis (2016) 214(Suppl 2):S44-50. doi:10.1093/infdis/jiw275

5. Paiardini M, Muller-Trutwin M. HIV-associated chronic immune activation. Immunol Rev (2013) 254:78-101. doi:10.1111/imr.12079

6. Rajasuriar R, Khoury G, Kamarulzaman A, French MA, Cameron PU, Lewin SR. Persistent immune activation in chronic HIV infection: do any interventions work? AIDS (2013) 27:1199-208. doi:10.1097/QAD. 0b013e32835ecb8b

7. Thompson M, Saag M, DeJesus E, Gathe J, Lalezari J, Landay AL, et al. A 48-week randomized phase $2 \mathrm{~b}$ study evaluating cenicriviroc versus efavirenz in treatment-naive $\mathrm{HIV}$-infected adults with $\mathrm{C}$-C chemokine receptor type 5-tropic virus. AIDS (2016) 30:869-78. doi:10.1097/QAD.0000000000000988

8. Lalezari J, Gathe J, Brinson C, Thompson M, Cohen C, Dejesus E, et al. Safety, efficacy, and pharmacokinetics of TBR-652, a CCR5/CCR2 antagonist, in HIV1-infected, treatment-experienced, CCR5 antagonist-naive subjects. J Acquir Immune Defic Syndr (2011) 57:118-25. doi:10.1097/QAI.0b013e318213c2c0

9. Covino DA, Sabbatucci M, Fantuzzi L. The CCL2/CCR2 axis in the pathogenesis of HIV-1 infection: a new cellular target for therapy? Curr Drug Targets (2016) 17:76-110. doi:10.2174/138945011701151217110917

10. Ansari AW, Heiken H, Meyer-Olson D, Schmidt RE. CCL2: a potential prognostic marker and target of anti-inflammatory strategy in HIV/AIDS pathogenesis. Eur J Immunol (2011) 41:3412-8. doi:10.1002/eji.201141676

11. Ansari AW, Kamarulzaman A, Schmidt RE. Multifaceted impact of host C-C chemokine CCL2 in the immuno-pathogenesis of HIV-1/M. tuberculosis co-infection. Front Immunol (2013) 4:312. doi:10.3389/fimmu.2013.00312

12. Ansari AW, Schmidt RE, Shankar EM, Kamarulzaman A. Immunopathomechanism of liver fibrosis: targeting chemokine CCL2-mediated HIV:HCV nexus. J Transl Med (2014) 12:341. doi:10.1186/s12967-014-0341-8

13. Refsland EW, Harris RS. The APOBEC3 family of retroelement restriction factors. Curr Top Microbiol Immunol (2013) 371:1-27. doi:10.1007/978-3642-37765-5_1

14. Stavrou S, Ross SR. APOBEC3 proteins in viral immunity. J Immunol (2015) 195:4565-70. doi:10.4049/jimmunol.1501504

15. Sheehy AM, Gaddis NC, Choi JD, Malim MH. Isolation of a human gene that inhibits HIV-1 infection and is suppressed by the viral Vif protein. Nature (2002) 418:646-50. doi:10.1038/nature00939

16. Berger G, Durand S, Fargier G, Nguyen XN, Cordeil S, Bouaziz S, et al. APOBEC3A is a specific inhibitor of the early phases of HIV-1 infection in myeloid cells. PLoS Pathog (2011) 7:e1002221. doi:10.1371/journal.ppat.1002221

17. Koning FA, Newman EN, Kim EY, Kunstman KJ, Wolinsky SM, Malim MH. Defining APOBEC3 expression patterns in human tissues and hematopoietic cell subsets. J Virol (2009) 83:9474-85. doi:10.1128/JVI.01089-09

18. Refsland EW, Stenglein MD, Shindo K, Albin JS, Brown WL, Harris RS. Quantitative profiling of the full APOBEC3 mRNA repertoire in lymphocytes and tissues: implications for HIV-1 restriction. Nucleic Acids Res (2010) 38:4274-84. doi:10.1093/nar/gkq174

19. Covino DA, Gauzzi MC, Fantuzzi L. Understanding the regulation of APOBEC3 expression: current evidence and much to learn. J Leukoc Biol (2018) 103:433-44. doi:10.1002/JLB.2MR0717-310R

20. Stopak KS, Chiu YL, Kropp J, Grant RM, Greene WC. Distinct patterns of cytokine regulation of APOBEC3G expression and activity in primary lymphocytes, macrophages, and dendritic cells. J Biol Chem (2007) 282:3539-46. doi:10.1074/jbc.M610138200

21. Sabbatucci M, Covino DA, Purificato C, Mallano A, Federico M, Lu J, et al. Endogenous CCL2 neutralization restricts HIV-1 replication in primary human macrophages by inhibiting viral DNA accumulation. Retrovirology (2015) 12:4. doi:10.1186/s12977-014-0132-6
22. Graziano F, Vicenzi E, Poli G. Plastic restriction of HIV-1 replication in human macrophages derived from M1/M2 polarized monocytes. JLeukoc Biol (2016) 100:1147-53. doi:10.1189/jlb.4AB0316-158R

23. Sharma S, Patnaik SK, Taggart RT, Kannisto ED, Enriquez SM, Gollnick P, et al. APOBEC3A cytidine deaminase induces RNA editing in monocytes and macrophages. Nat Commun (2015) 6:6881. doi:10.1038/ncomms7881

24. Gekonge B, Bardin MC, Montaner LJ. Short communication: nitazoxanide inhibits HIV viral replication in monocyte-derived macrophages. AIDS Res Hum Retroviruses (2015) 31:237-41. doi:10.1089/aid.2014.0015

25. Moris A, Murray S, Cardinaud S. AID and APOBECs span the gap between innate and adaptive immunity. Front Microbiol (2014) 5:534. doi:10.3389/ fmicb.2014.00534

26. Albin JS, Harris RS. Interactions of host APOBEC3 restriction factors with HIV-1 in vivo: implications for therapeutics. Expert Rev Mol Med (2010) 12:e4. doi:10.1017/S1462399409001343

27. Newman EN, Holmes RK, Craig HM, Klein KC, Lingappa JR, Malim $\mathrm{MH}$, et al. Antiviral function of APOBEC3G can be dissociated from cytidine deaminase activity. Curr Biol (2005) 15:166-70. doi:10.1016/j.cub.2004. 12.068

28. Vazquez-Perez JA, Ormsby CE, Hernandez-Juan R, Torres KJ, Reyes-Teran G. APOBEC3G mRNA expression in exposed seronegative and early stage HIV infected individuals decreases with removal of exposure and with disease progression. Retrovirology (2009) 6:23. doi:10.1186/1742-4690-6-23

29. Jin X, Brooks A, Chen H, Bennett R, Reichman R, Smith H. APOBEC3G/ CEM15 (hA3G) mRNA levels associate inversely with human immunodeficiency virus viremia. J Virol (2005) 79:11513-6. doi:10.1128/JVI.79.17. 11513-11516.2005

30. Kourteva Y, De Pasquale M, Allos T, McMunn C, D’Aquila RT. APOBEC3G expression and hypermutation are inversely associated with human immunodeficiency virus type 1 (HIV-1) burden in vivo. Virology (2012) 430:1-9. doi:10.1016/j.virol.2012.03.018

31. Ulenga NK, Sarr AD, Thakore-Meloni S, Sankale JL, Eisen G, Kanki PJ. Relationship between human immunodeficiency type 1 infection and expression of human APOBEC3G and APOBEC3F. J Infect Dis (2008) 198:486-92. doi: $10.1086 / 590212$

32. Land AM, Ball TB, Luo M, Pilon R, Sandstrom P, Embree JE, et al. Human immunodeficiency virus (HIV) type 1 proviral hypermutation correlates with CD4 count in HIV-infected women from Kenya. J Virol (2008) 82:8172-82. doi:10.1128/JVI.01115-08

33. Reddy K, Winkler CA, Werner L, Mlisana K, Abdool Karim SS, Ndung'u T, et al. APOBEC3G expression is dysregulated in primary HIV-1 infection and polymorphic variants influence CD4+ T-cell counts and plasma viral load. AIDS (2010) 24:195-204. doi:10.1097/QAD.0b013e3283353bba

34. Cho SJ, Drechsler H, Burke RC, Arens MQ, Powderly W, Davidson NO. APOBEC3F and APOBEC3G mRNA levels do not correlate with human immunodeficiency virus type 1 plasma viremia or CD4+ T-cell count. J Virol (2006) 80:2069-72. doi:10.1128/JVI.80.4.2069-2072.2006

35. Biasin M, Piacentini L, Lo Caputo S, Kanari Y, Magri G, Trabattoni D, et al. Apolipoprotein B mRNA-editing enzyme, catalytic polypeptide-like 3G: a possible role in the resistance to HIV of HIV-exposed seronegative individuals. J Infect Dis (2007) 195:960-4. doi:10.1086/511988

36. Gandhi SK, Siliciano JD, Bailey JR, Siliciano RF, Blankson JN. Role of APOBEC3G/F-mediated hypermutation in the control of human immunodeficiency virus type 1 in elite suppressors. J Virol (2008) 82:3125-30. doi:10.1128/JVI.01533-07

37. Zhao M, Geng W, Jiang Y, Han X, Cui H, Dai D, et al. The associations of hA3G and hA3B mRNA levels with HIV disease progression among HIVinfected individuals of China. J Acquir Immune Defic Syndr (2010) 53(Suppl 1): S4-9. doi:10.1097/QAI.0b013e3181c7d349

38. McBride JA, Striker R. Imbalance in the game of T cells: what can the CD4/ CD8 T-cell ratio tell us about HIV and health? PLoS Pathog (2017) 13: e1006624. doi:10.1371/journal.ppat.1006624

39. Sabbatucci M, Covino DA, Purificato C, Mallano A, Federico M, Lu J, et al. Erratum to: endogenous CCL2 neutralization restricts HIV-1 replication in primary human macrophages by inhibiting viral DNA accumulation. Retrovirology (2015) 12:47. doi:10.1186/s12977-015-0166-4

40. Boulware DR, Meya DB, Bergemann TL, Williams D, Vlasova-St Louis IA, Rhein J, et al. Antiretroviral therapy down-regulates innate antiviral response 
genes in patients with AIDS in sub-saharan Africa. J Acquir Immune Defic Syndr (2010) 55:428-38. doi:10.1097/QAI.0b013e3181ef4963

41. Katsounas A, Frank AC, Lempicki RA, Polis MA, Asmuth DM, Kottilil S. Differential specificity of interferon-alpha inducible gene expression in association with human immunodeficiency virus and hepatitis $C$ virus levels and declines in vivo. J AIDS Clin Res (2015) 6:410. doi:10.4172/2155-6113. 1000410

42. D’Antoni ML, Paul RH, Mitchell BI, Kohorn L, Fischer L, Lefebvre E, et al. Improved cognitive performance and reduced monocyte activation in virally suppressed chronic HIV following dual CCR2 and CCR5 antagonism. JAcquir Immune Defic Syndr (2018). doi:10.1097/QAI. 0000000000001752
Conflict of Interest Statement: EL and SS are employees of Allergan. All other authors: no potential conflicts of interest.

The reviewer LL and handling Editor declared their shared affiliation.

Copyright $\odot 2018$ Covino, Purificato, Catapano, Galluzzo, Gauzzi, Vella, Lefebvre, Seyedkazemi, Andreotti and Fantuzzi. This is an open-access article distributed under the terms of the Creative Commons Attribution License (CC BY). The use, distribution or reproduction in other forums is permitted, provided the original author(s) and the copyright owner(s) are credited and that the original publication in this journal is cited, in accordance with accepted academic practice. No use, distribution or reproduction is permitted which does not comply with these terms. 